\title{
Transportation System Analysis at the Major Road Intersection in the CBD Area of Rangpur City, Bangladesh
}

\author{
Jakirul Islam Jony Prothan, Marazul Islam*, Atikur Rahman, Ashrafuzzaman Pramanik \\ Department of Urban and Regional Planning, Pabna University of Science and Technology, Pabna, Bangladesh \\ Email address: \\ marazu1120923@gmail.com (M. Islam), jakirpstu12@gmail.com (J. I. J. Prothan), atikurp121714@gmail.com (A. Rahman), \\ ashraf.pramanik@gmail.com (A. Pramanik) \\ ${ }^{*}$ Corresponding author
}

\section{To cite this article:}

Jakirul Islam Jony Prothan, Marazul Islam, Atikur Rahman, Ashrafuzzaman Pramanik. Transportation System Analysis at the Major Road Intersection in the CBD Area of Rangpur City, Bangladesh. International Journal of Transportation Engineering and Technology.

Vol. 3, No. 4, 2017, pp. 74-82. doi: 10.11648/j.ijtet.20170304.15

Received: September 27, 2017; Accepted: October 23, 2017; Published: December 14, 2017

\begin{abstract}
Traffic and transportation management is a major challenge for a city in Bangladesh. Moreover, this challenge is so critical to managing of traffic and transport at a Central Business Area (CBD) in a city like Rangpur. The main objectives of this study are to find out the present problems of traffic and transportation and discussion on way of an effective solution. So, the angle of different intersections, flow analysis of roads, level of service (LOS) analysis of selective roads and physical feature analysis at the CBD area is conducted for this study. To find out the condition of traffic and transportation at CBD area different type of survey have been done like traffic volume survey, physical feature survey, delay time survey, parking survey. Collected data analyzed by using MS Excel software and design or pictorial data analyzed by using GIS software, Google Sketch-up software. The main problems at the CBD area are informal occupancy, violet setback rules, no minimum sight distance for a vehicle, lack of proper use of footpath, inappropriate channelization of vehicles.
\end{abstract}

Keywords: Traffic Congestion, Intersections \& CBD

\section{Introduction}

Bangladesh is a rapid move to an industrial country, city streets do not reach to function at its satisfactory level. Different classes of vehicles such as cars, vans, buses, tracks, auto- rickshaw, motorcycles, by- cycles, bullock carts, etc. are found to use the common roadway facilities without segregation on most of the roads in developing countries like Bangladesh [11]. A better transportation circulation system is very much important for every nation and its rapid demand of economic, industrial, trade etc. The efficiency of an urban transport system is greatly influenced by its circulation management system, Circulation management is very important for efficient functioning of road transport [1]. The urban transportation problem is actually a complex bundle of interrelated problems [2]. They can be grouped into three categories: congestion, mobility, and ancillary impacts. Traffic congestion, delays, noisy and unpleasant traffic way, anxiety for road accident, inaccessible and unpleasant pedestrian ways, these are common problems for every street [3]. The city corporation is located in the north-western part of Bangladesh. The present area is 203.19 Sq.Km and population are about 10 Lac [4]. Effective traffic and transportation management system are required at CBD area in Rangpur city. To increase the capacity and to ensure condition for smooth traffic movement immediate attention is required for the streets. The study will out the existing deficiencies of the traffic management system.

Important Intersections at CBD Area
a) Jahj Company Intersection
b) Payirachottor Intersection
c) Supermarket Intersection
d) Townhall Intersection 


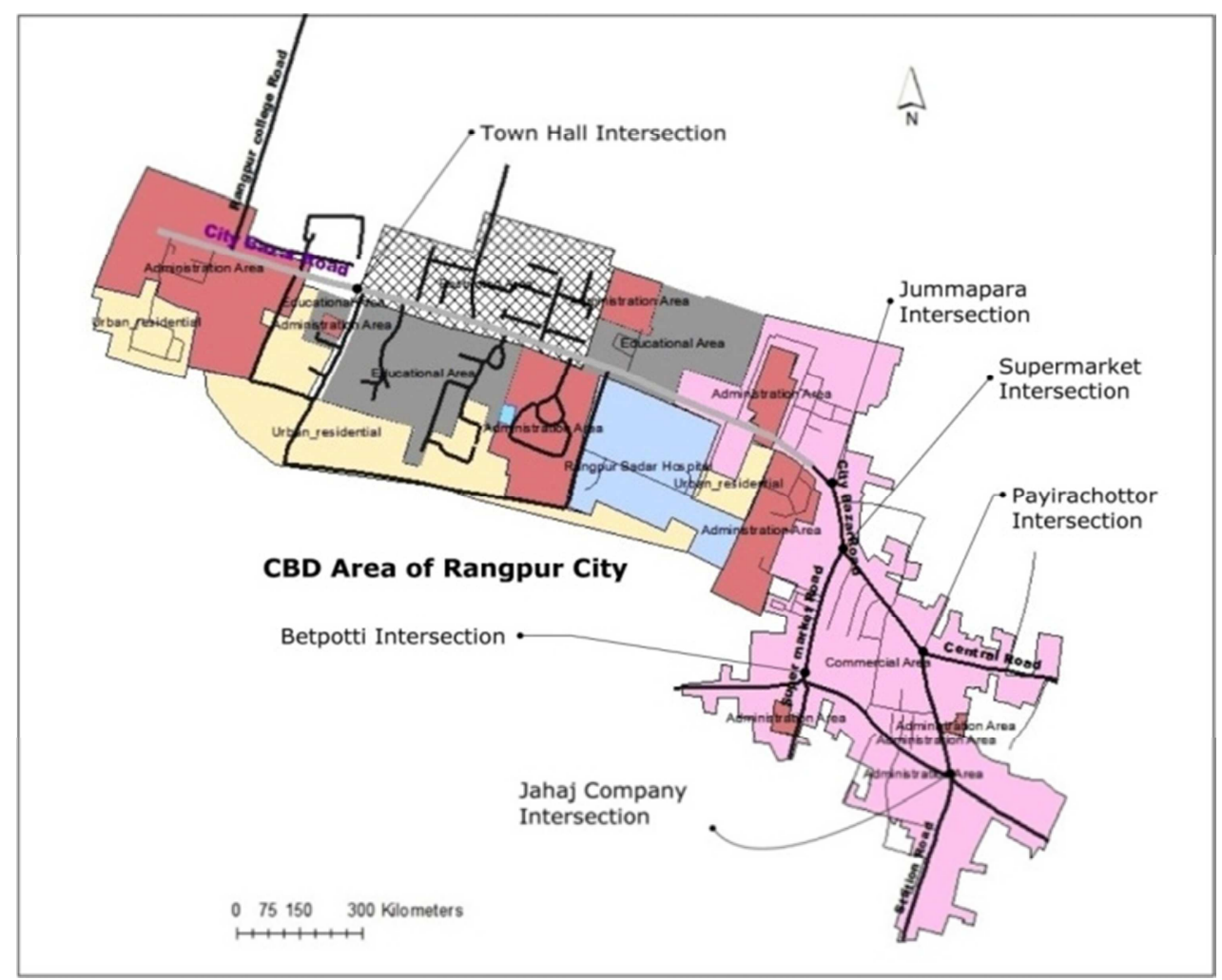

Figure 1. Important Intersections at CBD Area.

\section{Literature Review}

Identified some congestion points and also discuss the causes of traffic congestion in Dhaka city. This study also finds out the problems of different intersection point like road and rail line. This study introduces authors experience and tries to the solution of the present traffic problems. The study also finds out the violet of traffic and transportation laws in Dhaka city. On the basis of geometric methods and ways are trying to solution of present horrible traffic and transportation situation in Dhaka city. On the basis of this study, a new data is found out that rickshaw is not the major causes of traffic jam in Dhaka city [5]. In Dhaka, the traffic congestion cost is US\$3 billion a year and the city losses over 8 million work hours daily [10]. Traffic control point and locate some traffic congestion point in Khulna city at $\mathrm{CBD}$ area. To control this situation provide some policies and guidelines. This study provides some idea about intersection management. This report mainly shows discuss the general causes and solution to traffic congestion of congesting points. It also provides some traffic related problem solution for selective intersection in Khulna city [6]. Parking and their types are different in various conditions. It is also helpful for parking survey. The modeling process, transport design, and survey procedure are clearly described this book. Detail design and methods are the main focus of this book [7].

\section{Material and Method}

A physical feature survey is conducted at the CBD area for find out the density of market area beside the main road at CBD area in Rangpur city. On the basis of Highway Capacity Manual (HCM) traffic flow is analyzed the roadways. Level of Service of delay time survey is an important indicator to understand the nature of traffic flow on the road. Delay time survey is conducted on different roads on the basis of the respective intersection. A vehicle is going throughout each intersection at a time both directions. One kilometer distance of the roadway is considered from each intersection point. Than Measure the angle between roads at an intersection on the basis of American Association of State Highway and Transportation Official.

\section{Data Analysis and Findings}

\subsection{Physical Feature Survey}

On the basis of physical feature survey market and important building, density is shown on the map. Mainly three factors are considered for preparation of the map. These are:

(a) Building or market situated beside the major road or not.

(b) Parking space is available or not

(c) Building must be used only commercial activities

In the density map, dark color shows the highest density of market. The yellow color is shown the densely market area of CBD. Light green color is show some marketplace besides the road which is not filling up above three factors. The blue color is shown the normal density of market at the CBD area. 


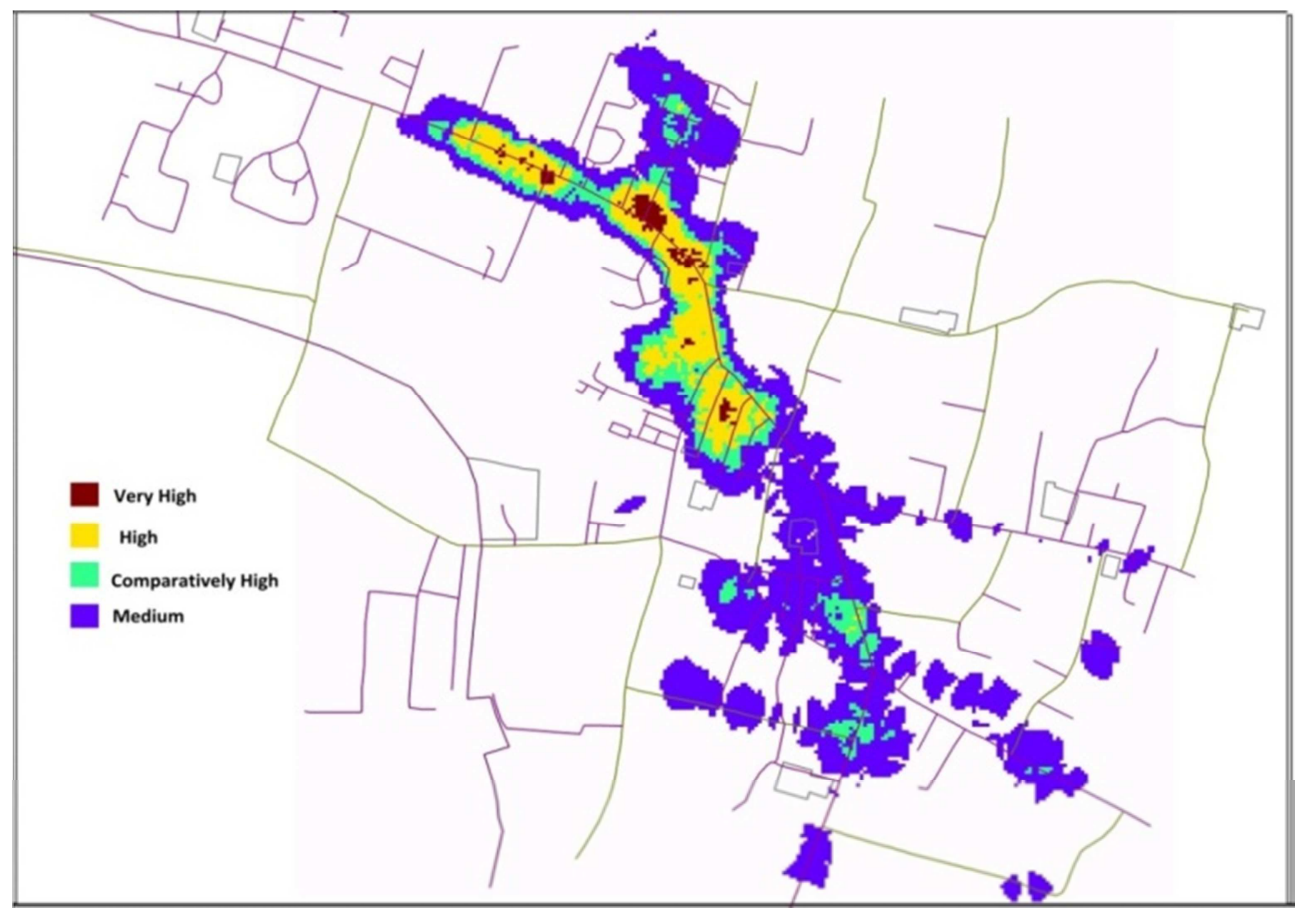

Figure 2. GIS-Based Density Map of Market Area.

\subsection{Standard Angle Analysis at Intersections in CBD Area}

The minimum angle of an intersection should not be less than $65^{\circ}[8]$. For the functional intersection, the angle range must be within $80^{\circ}$ to $120^{\circ}$ [8].

(1) Angle between the Roads of Jahaj Company Intersection

The angle between Station road and G.L. Roy road (Shapla chottor to G.L. Roy road direction) is $75^{\circ}$ which are $5^{0}$ less than the standard. Another angle between Station road and
G.L. Roy road (City bazar to G.L. Roy road direction) is $140^{\circ}$ which is $20^{\circ}$ excess than the standard angle. The Los delay time survey is C. Angle between Station road and Dwanbari road (Shaplachottor to Dwanbari road direction) is $108^{\circ}$ and LOS of delay time survey at 9-10am, 2-3pm, 45 pmof the Dwanbari road is C. Again angle between Station road and Dwanbari road (Dwanbari Road to Station Road towards city bazar) is $52^{0}$ this angle is $25^{\circ}$ below the standard.

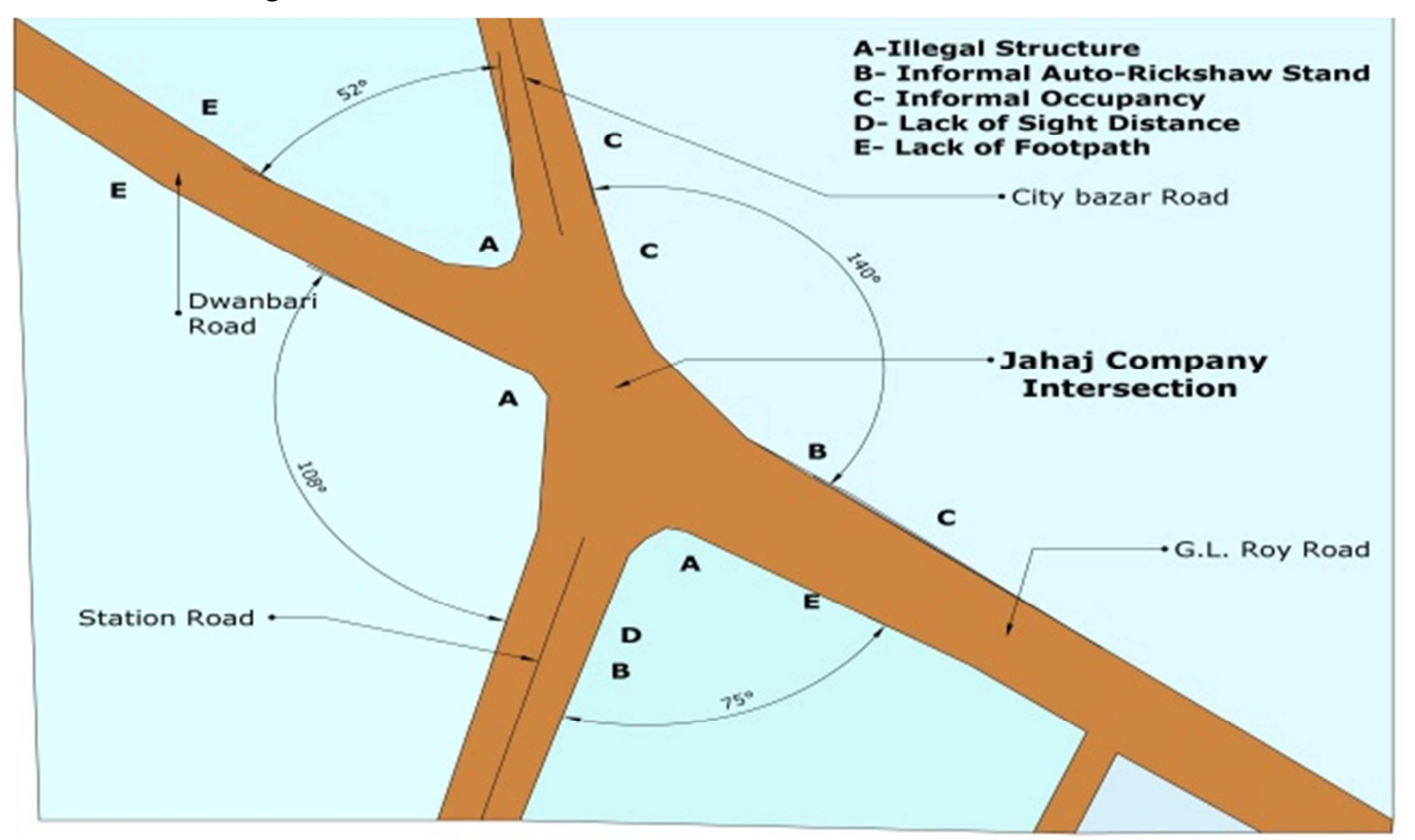

Figure 3. The angle between Roads of Jahaj Company Intersection. 


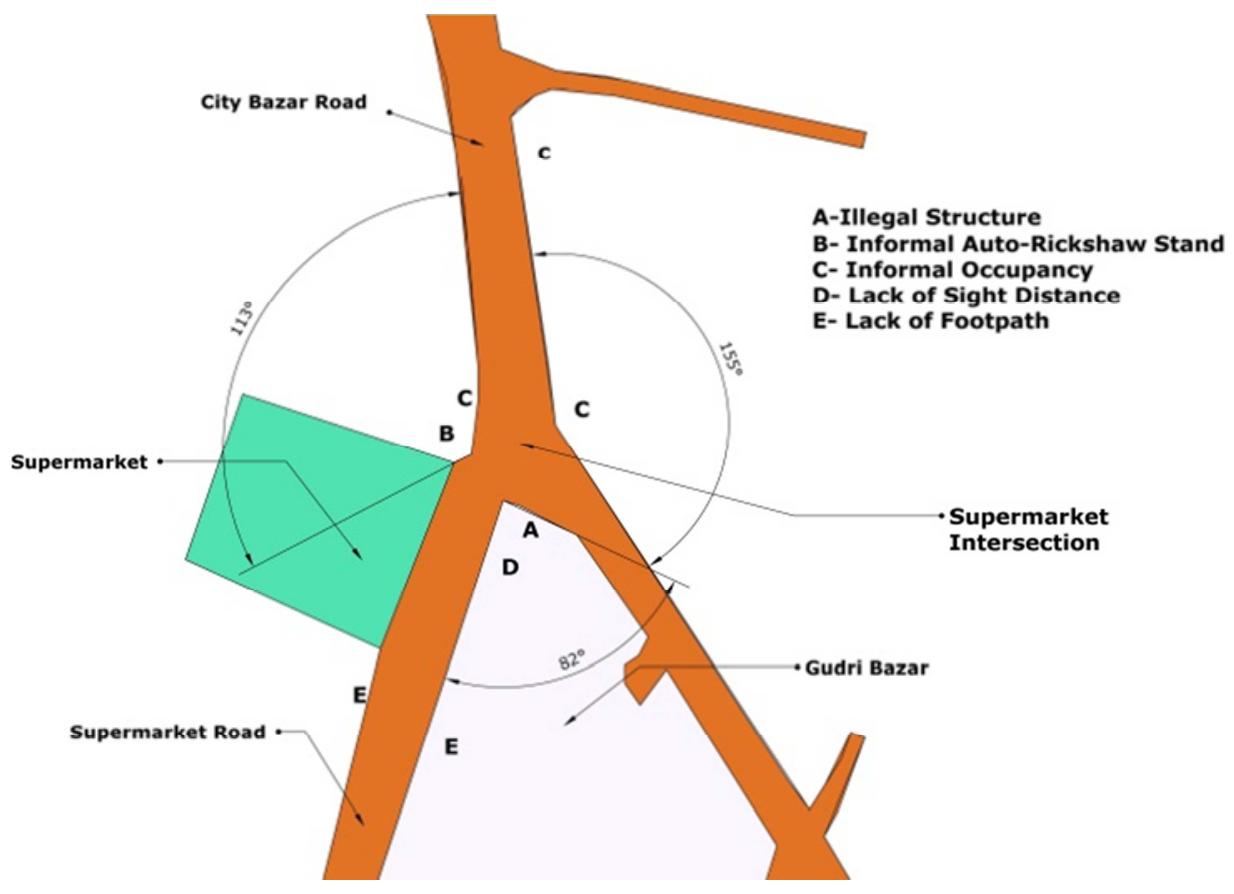

Figure 4. The angle between Roads of Supermarket Intersection.

(2) Angle between the Roads of Supermarket Intersection The angle between Station road and Central road (towards supermarket) is $155^{\circ}$ this is $45^{\circ}$ excess and the LOS of the delay time survey at $9-10 \mathrm{am}$ is $\mathrm{C}$. Moreover there is no footpath and informal occupancy occurred in Supermarket road. Huge parking occurs for Guidry Bazar, Supermarket, and Mini supermarket. There are no minimum $18 \mathrm{ft}$ sight distance in front of the supermarket.

(3) Angle between the Roads of Payirachottor Intersection The angle between Station Road and the Central road is $161^{\circ}$ it is $41^{\circ}$ excess. Supermarket Los at 9-10am, 2-3pm, 4$5 \mathrm{pm}$ is C. Again Station road to City Bazar road angle is $157^{\circ}$ which is $37^{\circ}$ excess in respect of standard.

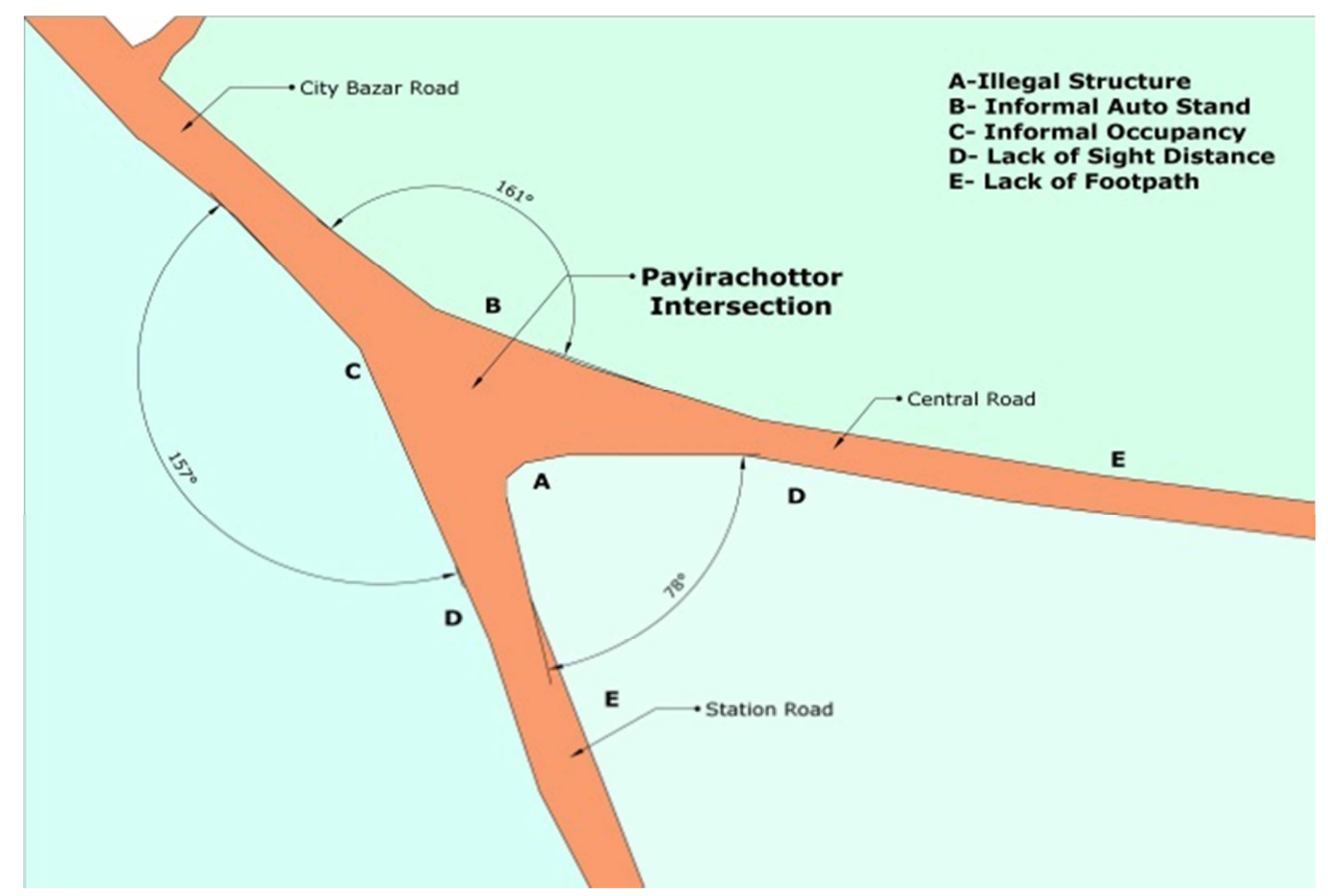

Figure 5. The angle between Roads of Payira chottor Intersection.

(1) Angle between the roads of Town Hall Intersection

The minimum angle of a functional intersection range must be within $80^{\circ}$ to $120^{\circ}$ according to standard. So this intersection is perfect for vehicle movement. 


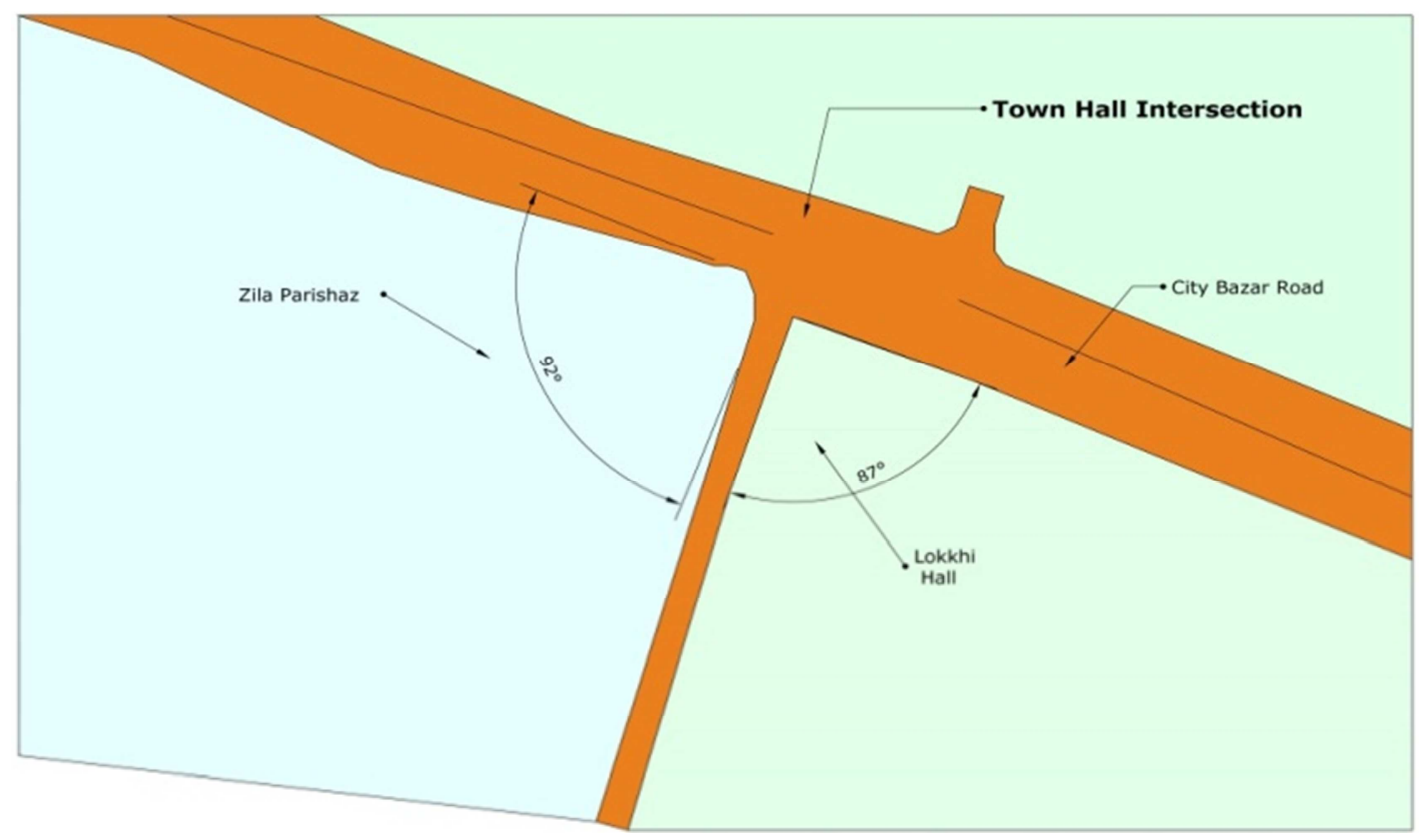

Figure 6. The angle between Roads of Town Hall Intersection.

(2) Angle between Roads of Jummapara Intersection

The angle between Jummapara roads and City Bazar road $131^{0}$ which is $11^{0}$ excess from the standard. On the other hand, City Bazar road to Jummapara road angle is $56^{\circ}$ it is
$24^{0}$ less than the standard. Also, Supermarket road to Station road angle is $152^{\circ}$ which is $32^{\circ}$ excess from the standard angle. Jummapara road to Station road is $8^{0}$ less from the standard.

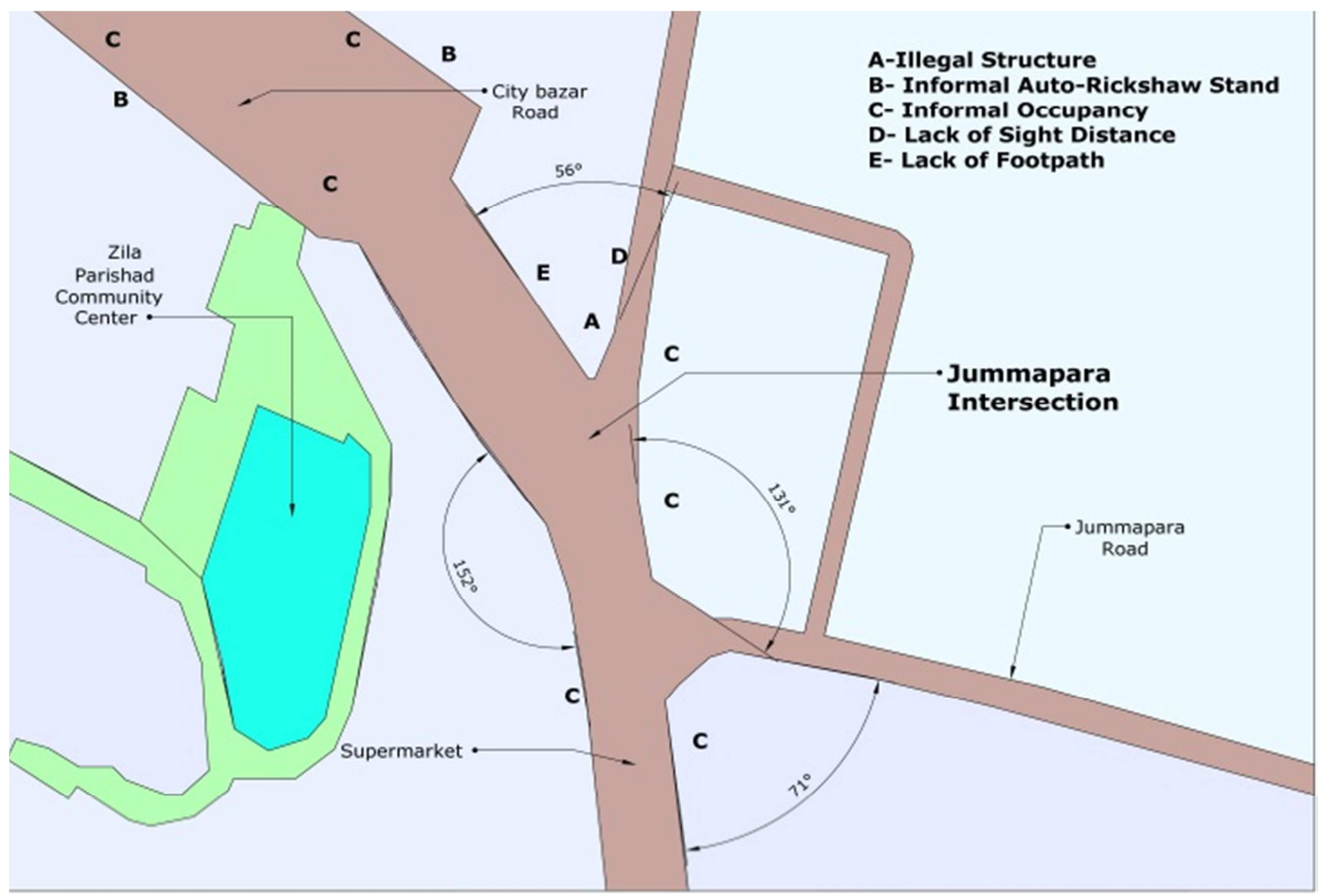

Figure 7. The angle between Roads of Jummapara Intersection.

\subsection{Delay Time Survey at Different Intersection}

Delay time of a vehicle is called as the difference in travel time between when a vehicle is unaffected or affected by the different interruption in the road.
(1) Delay Time at Jahaj Company Intersection

This is the busiest intersection in the CBD area in Rangpur city. This intersection is jointed southern part and eastern part of the city to the rest of the city. Total travel time of the intersection is 22 minutes. 


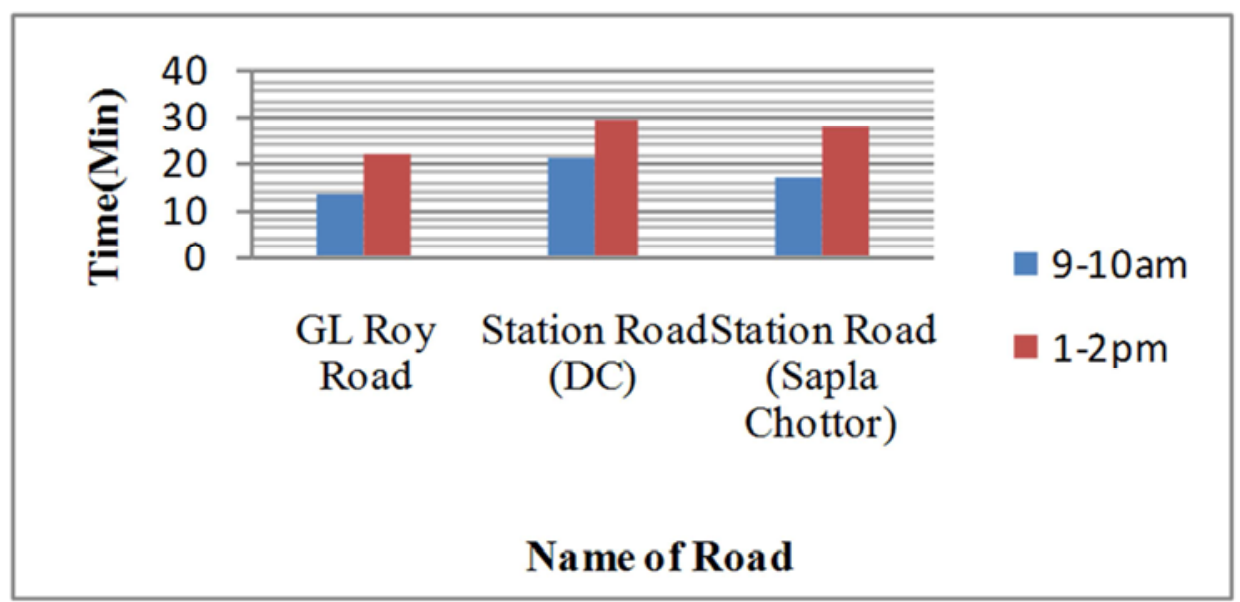

Figure 8. Delay Time Data of Jahaj Company Intersection.

(2) Delay Time at Payira chottor Intersection

Total three roads intersect at the payira intersection. Travel time is gradually increased from morning to noon of the day. More or less 24 Munities is spending for passing this intersection.

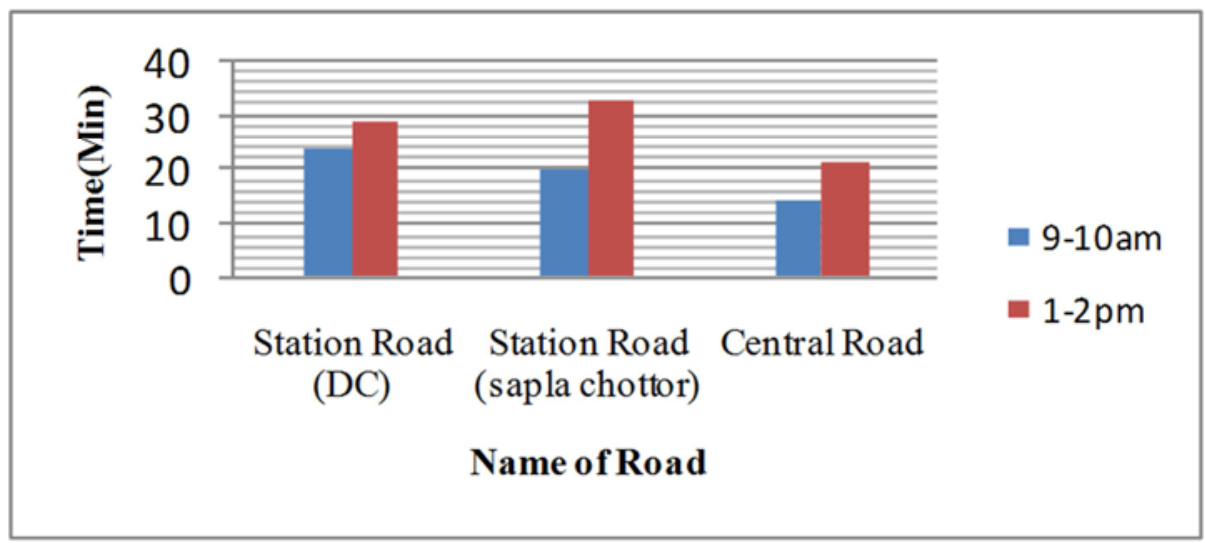

Figure 9. Delay Time Data of Payira chottor Intersection.

(3) Delay Time at Supermarket Intersection

Two roads intersect at Supermarket intersection one is Station road and another is Supermarket road. Travel time is gradually increased from morning to noon of the day. More or less 21 Munities is spending for passing this intersection.

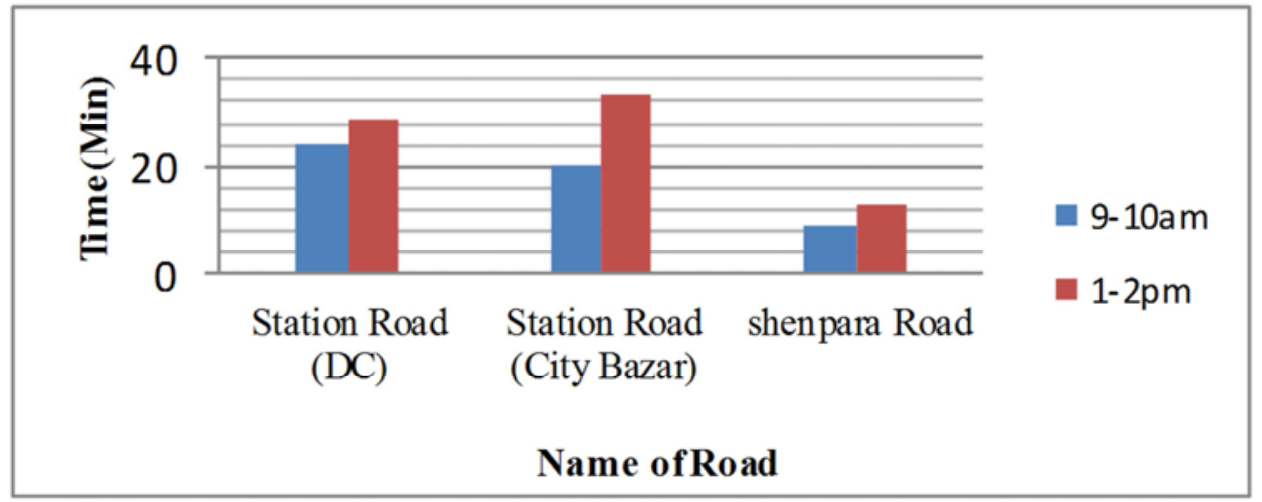

Figure 10. Delay Time Data of Supermarket Intersection.

(4) Level of Service (LoS) of Different Intersections Highway Capacity Manual (HCM) fixed the Level of Service (LoS) for signalized and un-signalized intersection.
The LoS of different intersections at CBD in Rangpur city is calculated by using the standard. 
Table 1. Standards to Determine of Level of Service (LoS).

\begin{tabular}{llll}
\hline $\begin{array}{l}\text { Level of } \\
\text { Service }\end{array}$ & Significance & $\begin{array}{l}\text { Signalized } \\
\text { Intersection }\end{array}$ & $\begin{array}{l}\text { Un-signalized } \\
\text { Intersection }\end{array}$ \\
\hline A & Free flow & $\leq 10 \mathrm{sec}$ & $\leq 10 \mathrm{sec}$ \\
$\mathrm{B}$ & Reasonably free flow & $11-15 \mathrm{sec}$ & $11-15 \mathrm{sec}$ \\
C & Stable flow & $16-25 \mathrm{sec}$ & $16-25 \mathrm{sec}$ \\
D & Approaching Unstable flow & $26-35 \mathrm{sec}$ & $26-35 \mathrm{sec}$ \\
E & Unstable flow & $36-45 \mathrm{sec}$ & $36-45 \mathrm{sec}$ \\
F & Breakdown & $\geq 45 \mathrm{sec}$ & $\geq 45 \mathrm{sec}$ \\
\hline
\end{tabular}

Source: Authors' Compilation Based on [9]

According to the Highway capacity Manual, the traffic flow of different intersection at the CBD area is given below.

Table 2. Level of Service (LoS) at Intersections in CBD Area.

\begin{tabular}{llll}
\hline \multirow{2}{*}{ Name of Intersection } & $\begin{array}{l}\text { Total } \\
\text { Time(Min) }\end{array}$ & $\begin{array}{l}\text { Total } \\
\text { Time(Sec) }\end{array}$ & LoS \\
\hline Jahaj Company Intersection & 22 & 22 & $\mathrm{C}$ \\
Payira Intersection & 24 & 24 & $\mathrm{C}$ \\
Supermarket Intersection & 21 & 21 & $\mathrm{C}$ \\
\hline
\end{tabular}

Source: Authors' Compilation Based on [9]
Overall condition of the traffic flow is not good enough in the CBD area. The condition of the entire road is just below the danger level. It also indicates the alarm of huge congestion next few years.

\section{Recommendation}

\subsection{Proposed Vehicle Movement Route at CBD Area in Rangpur City}

(1) New Route for Vehicle Movement

A new one-way circulation route should have fixed. The auto and rickshaw shall move from G.L. Roy road to Townhall intersection by using Dewanbari road.

(2) Remove Temporary auto Stand on Existing Route

Temporary auto stand in front of the Supermarket must have restricted as well as in front of Payirachottor intersection and Jahaj Company intersection.

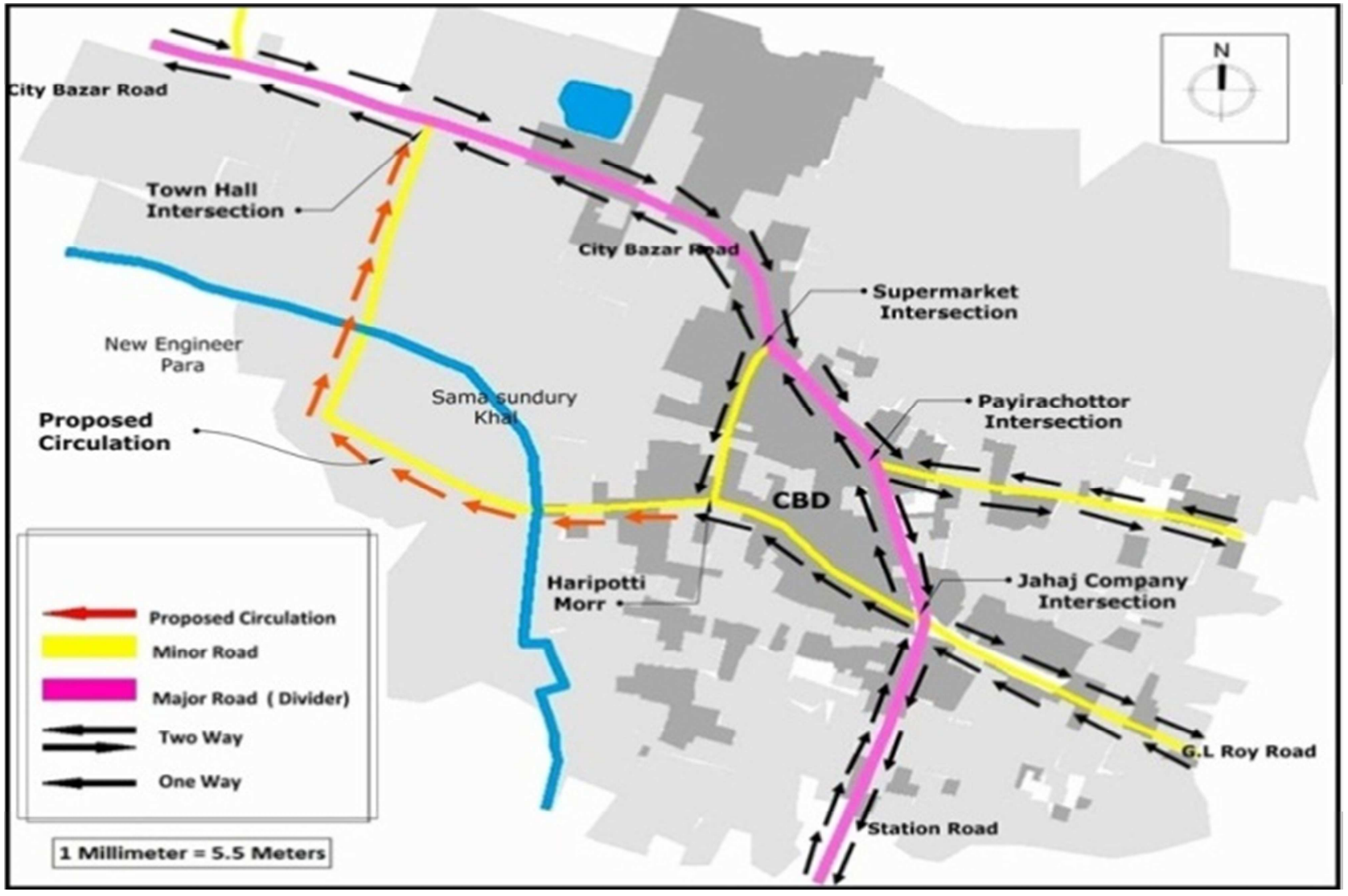

Figure 11. Proposals for Jahaj Company Intersection.

\subsection{Proposal for Major Intersections at CBD Area}

Intersections of CBD area are the key area for traffic and transportation management of CBD in Rangpur city. If all the intersections are appropriately working than the whole CBD is worked appropriately.

(1) Jahaj Company Intersection

This intersection is one of the major intersections of the CBD area. The entire commercial and business center is situated here so some initiative should introduce here for effective traffic and transportation management.

It is very clear that some illegal structure is created the traffic problem and obviously, standard side distance must be introduced as well as the standard angle between two roads must be followed. 


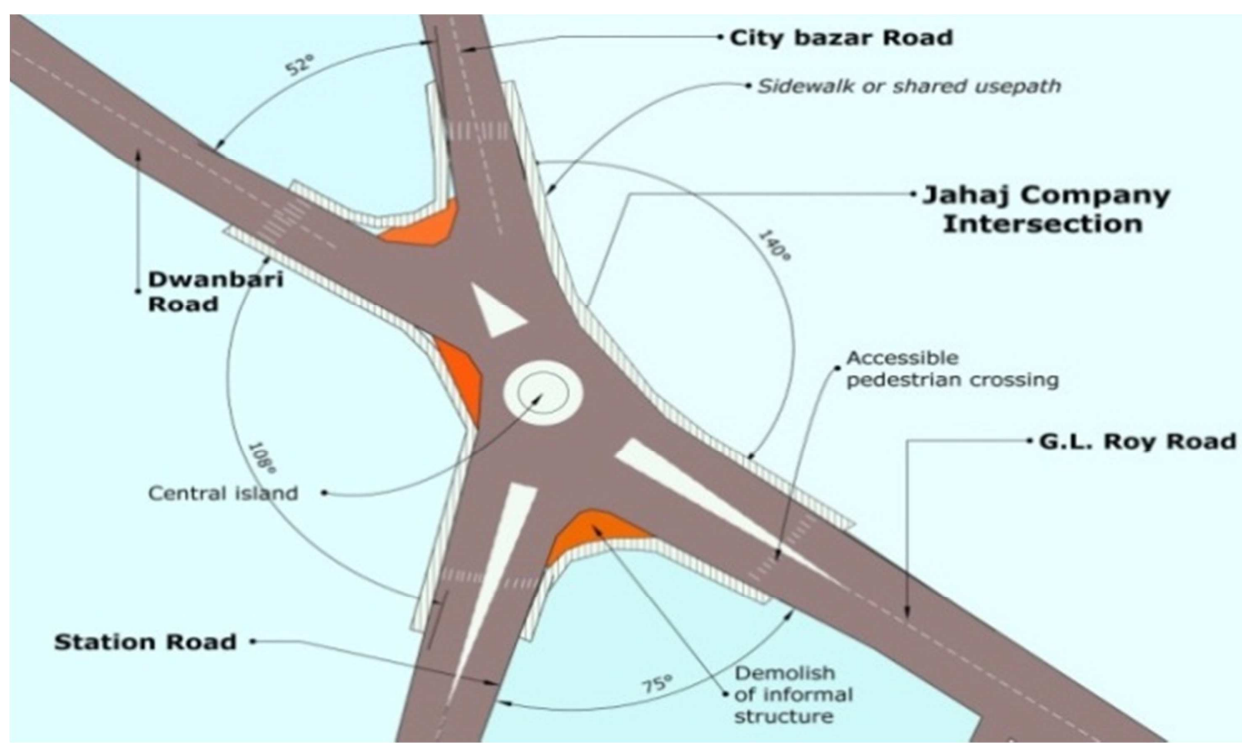

Figure 12. Proposals for Jahaj Supermarket Intersection.

(2) Supermarket Intersection

The supermarket is one of the busiest places. Moreover, Gudribazar is situated here which is a largest wholesale market in the town. There is no footpath in front of Gudribazar. So some initiatives are:

(a) On Street Parking

A parking lot should perfectly introduce in front of the supermarket. Angular parking is appropriate for supermarket area.

(b) New Footpath
There is no footpath in front of Gudribazar. So a footpath should construct beside the supermarket road.

(3) Jummapara Intersection

There are some initiatives should be taken for improvements of the present condition. These are Parking Restricted Area. Parking should restrict on the road in front of Zila Parishad community center and Pouro supermarket. Of street parking Space. The open space of Zila Parishad Community center should use for of street lot.

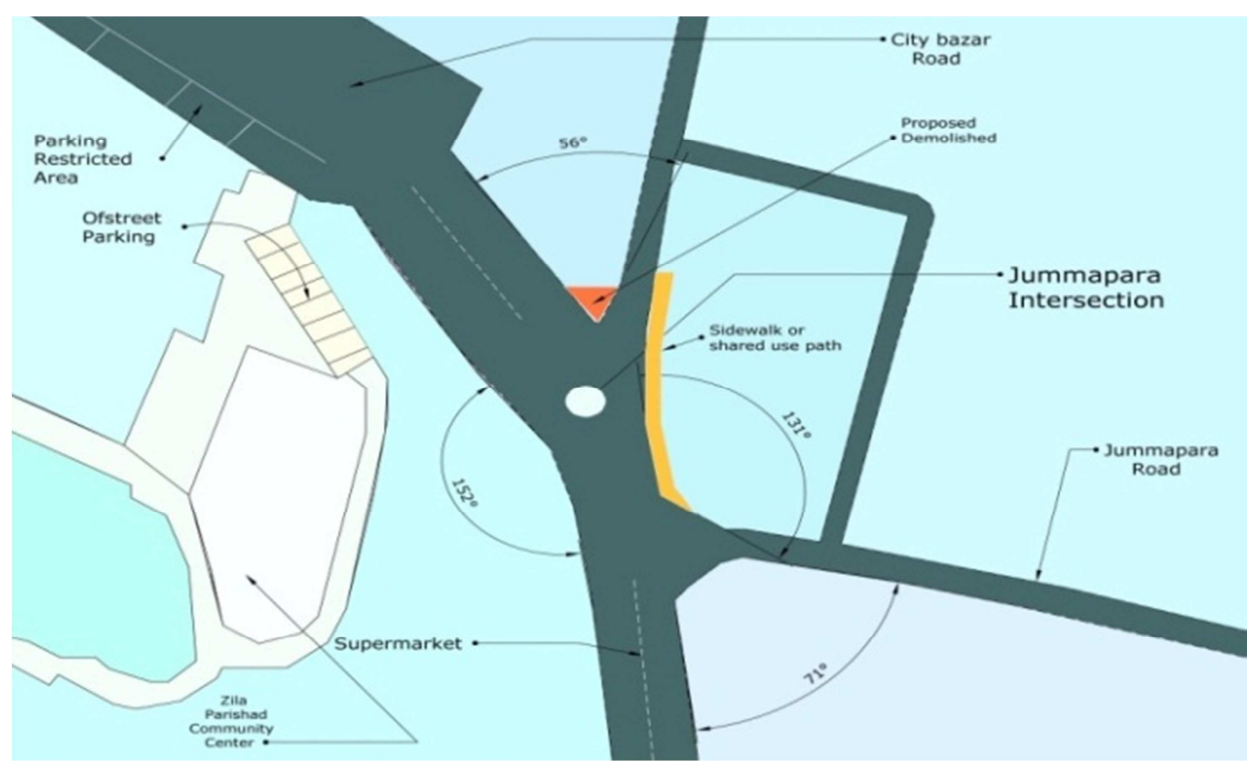

Figure 13. Proposals forJummapara Intersection.

(4) Payira chottor Intersection

This intersection is one of the major intersections of the CBD area. The entire commercial and business center is situated here so some initiative should introduce here for effective traffic and transportation management. These are:

(a) New Sidewalk
A new sidewalk should construct beside road of the north and southern part of the Payira sculpture.

(b) Pedestrians Crossing

A part of the roads should use for the purpose of pedestrian crossing. The places of crossing shown in the figure. 


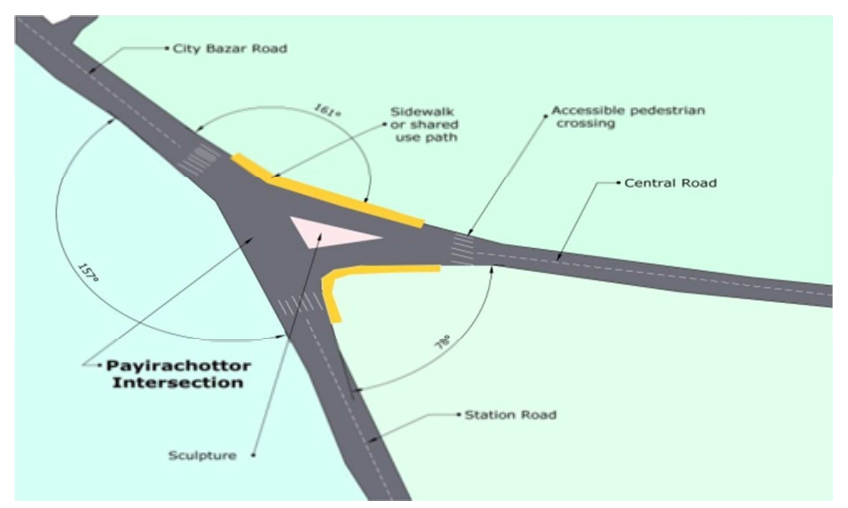

Figure 14. Proposals for Payira chottor Intersection.

\section{Acknowledgements}

At first all the author wishes to express her deepest gratitude to the almighty Allah for giving this opportunity and for enabling them to complete the research successfully.

We are grateful to Md. Nazrul Islam, Assistant Town Planner of Rangpur City Corporation for provide us some effective information and data about study area. Several people and organizations were helpful in providing data and information used in this study.

At last, A special thanks goes to BRTA, authority of RCC, GE Dept. of Begum Rokeya University, Rangpur for provide us informative secondary information related to our study area.

\section{References}

[1] Bently, I. et. al. (2001). Responsive Environments; A Manual for Designers, Architectural Press, England.

[2] Dimitrion, H. T. (1992). Land Use and Transportation Interaction, UTM Publishers, New York, United States.

[3] Gallion, A. B. (1998). The Urban Pattern: City Planning and Design, CBS publishers \& distributors, New Delhi, India.

[4] Rangpur City. (n.d.). In Wikipedia. Retrieved September 18, 2017, from https://en.wikipedia.org/wiki/Rangpur_City

[5] Meenar, R. M. M. (2000). Traffic Congestion in Dhaka City: where is the solution Term paper for the Coarse PD 592: Infrastructure and Transport Planning, Department of planning, Sunny Buffalo, May 10, 2000.

[6] Khulna Development Authority (KDA), Bangladesh. (2001) Draft final report Vol. 3. Preparation of structure plan, Master plan and Detail Area plan for Khulna City, Khulna.

[7] Wells, G. R. (1975). Comprehensive Transport Planning. Charles Griffin Company Ltd, London Press, Chicago, USA.

[8] American Association of State Highway and Transportation Official (AASHTO). (2012). Guide for the planning, design, and Operation of pedestrian Facilities. Washington, D.C.

[9] HighwayCapacity Manual (HCM), (2010). Special Report 209, Transportation Research Board, National Research Council.

[10] Khan, S. M., \& Hoque, M. S. (2013). Traffic Flow
Interruptions in Dhaka City: Is Smooth Traffic Flow Possible? Journal of Presidency University, 2(2), 46-54.

[11] Saha, A. K., Ahmed, B., Rahman, M., \& Nahar, T. T. Analysis of Traffic Congestion and Remedial Measures at Traffic Mor in Pabna City, Bangladesh.

\section{Biography}

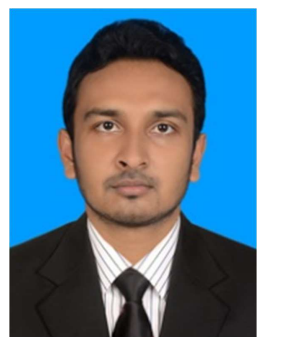

Md. Jakirul Islam Jony Prothan graduated from Pabna University of Science and Technology (PUST), Pabna, Bangladesh in Urban and Regional Planning in 2017. His research interest areas: transportation engineering, GIS and remote sensing.

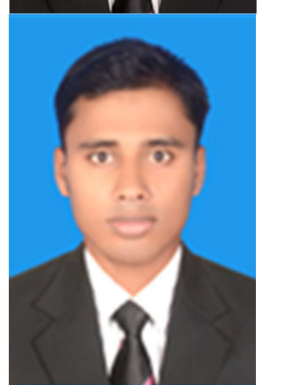

Md. Marazul Islam graduated from Pabna University of Science and Technology (PUST), Pabna, Bangladesh in Urban and Regional Planning in 2017. His research interest areas: transportation engineering, Geo- informatics.

Md. Atikur Rahman graduated from Pabna University of Science and Technology (PUST), Pabna, Bangladesh in Urban and Regional Planning in 2017. His research interest areas: traffic and transportation management, GIS and development studies

Md. Ashrafuzzaman Pramanik $\mathrm{He}$ is an Assistant Professor and Chairman, Department of Urban and Regional Planning, Pabna University of Science and Technology, Pabna, Bangladesh. He completed his undergraduate in URP from Khulna University, Bangladesh and M.Sc. in EESI (KTH, Sweden). His research interest areas are Urban Environmental Management, Water Resource Management, and Urban Planning. 